\title{
CULTURE-INCLUSIVE TOILET DESIGN FOR YPAB BLIND SCHOOL IN SURABAYA
}

\author{
TANUWIDJAJA, Gunawan \\ Department of Architecture, Petra Christian University \\ Jalan Siwalankerto 121-131, Surabaya 60236, INDONESIA \\ Email: gunte@petra.ac.id,gunteitb@yahoo.com
}

\begin{abstract}
Toileting culture affects the toileting design. Adaptive - inclusive toilet design strategy was needed to respond the local unique toileting culture of Surabaya people. Based on toileting culture and five Inclusive design principles directed by Tanuwidjaja, the inclusive toilet was produced. The project involved four steps such as: literature review, interview and photo documents, participative design workshops and design development. Therefore, a final design was produced and found acceptable for Surabaya people.
\end{abstract}

Keywords: Adaptive; inclusive; toileting culture; squatting; sitting; UNDK.

\section{INTRODUCTION}

The University Network of Digital [Local] Knowledge (UNDK); a network of universities in Indonesia aiming to mainstream priority the local knowledge and equip them with digital tools \& resources; is producing a mini project to explore local culture and supported by United Board of Christian Higher Education Association (UBCHEA) (http:// undk.asia/).

The Petra Christian University was involved in the UNDK Mini Project in 2013 with the title of "Portraying the Toileting Culture of Surabaya People: People Perception and Toilet Design Diversity".

The Goals of the Project were:

- to find the toilet users of Surabaya in several locations (in the scope)

- to find and document the toileting behaviour of Surabaya people

- to find types of toilets were available in Surabaya (in the Residential and Kampong Settlement, Public Toilets and Private Toilets)

- to produce comics or illustration for diverse healthy toileting for Surabaya

- to find the design strategy to provide locally friendly toilets but also healthy and accessible

The mini project involved 8 lecturers and 325 students, from three Study Programs/Departments (Architecture, Visual Communication Design and English Literature), producing:

- Documentation of Toileting Culture with interview, sketches, photo documentation, google map and $\mathrm{x}$-banner
- Video of Toileting Culture

- Theatre Performance symbolizing the Toileting Culture

- Design Model of Inclusive Toilet for Indonesian

Only, the inclusive design toilet would be explained, while the rest of the project could be read in our UNDK Petra Website (http://undkpetra. wordpress.com/).

\section{LITERATURE REVIEW}

The toileting process was found as an important part in the human live especially related to as described by Greed (2003). Toilets were seen as an integral and important component of modern urban design and town planning policy, at citywide, local area and individual site level.

The provision of public toilets related to range of issues: crime and vandalism; sexuality; the environment, water conservation and global sustainability; health, hygiene and medicine; women's issues, childcare, breastfeeding and sanpro disposal; public transport and private travel; leisure, tourism and sport; continence, disability and ageing; architecture, engineering and design; sewerage, drainage and plumbing; religion, culture and taboo (Greed, 2003).

Cummings (2000) found a closer accounting of the bathroom and the cross-cultural interaction, ethnographic experience, as well as cultural commensurability. In the bathroom, cultural difference was accentuated to the point where the spectre of incommensurability arises. 
Inclusive design is defined as "The design of mainstream products and/or services that are accessible to and usable by, as many people as reasonably possible without the need for special adaptation or specialized design." Inclusive design should be included in the earliest design process (The British Standards Institute, 2005, quoted in http:// www-edc.eng.cam.ac.uk/betterdesign)

The users' involvement in the design process becomes crucial because its principles of user centred, population awareness and business focused. A successful implementation of inclusive design can result in a product that is functional, usable, desirable, and ultimately profitable (http://www-edc.eng.cam.ac. uk/betterdesign/).

To complement the inclusive design approach, some universal design principles were also adopted, such as: equitable use, flexibility in use, simple and intuitive use, perceptible information, tolerance for error, low physical efforts, and size and shape for approach and use, would improve liveability and quality of life for everyone (Preiser and Ostroff, 2001).

\section{RESEARCH METHOD}

The inclusive design process was conducted with several steps:

- Simple Literature Review

- Interview and Photo Documentation

- Participative Design Workshop

- Design Development

The Literature Review was conducted to understand the importance of toileting culture and toileting need especially in the design aspect.

Two toilet design projects were chosen, the toilet for the blind school and toilet for the riverside villagers. But only the blind school toilet was discussed further.

Toileting culture exploration was conducted by the students in their own homes (a senior women, grandfather, and helpers). Furthermore, exploration was extended to other users in other places, such as: the blind students in the blind school, the village residents, and the mall visitors. The exploration took 2 months using visual research methods [photo, video and questionnaire] (http://undkpetra.wordpress.com/, http://desaininklusiukpetra.wordpress.com/).

A participative toilet design workshop was conducted in collaboration with $\mathrm{C} 2 \mathrm{O}$ Library and Ayorek! It was conducted in the small group, guided by the lecturer, followed by resource persons, students, and common people. Two resource persons involving in the workshop were Mr. Tutus Setiawan
SPd. (the blind person) and Mr. Ahmad Fauzi M.Hum. (cerebral palsy person). Therefore, the workshop enriched the knowledge of inclusive design students.

The toilet design was developed by the students and lecturer, considering five principles (compressed from the seven principles of universal design and three principles of inclusive design). The design was conducted within a month. To confirm the usability, a role-play using the design was conducted by suitable students.

Further, the design was exhibited and published to the people using Surabaya's Toileting Culture Exhibition (Njedhing Nang Suroboyo) held in Petra Christian University Library.

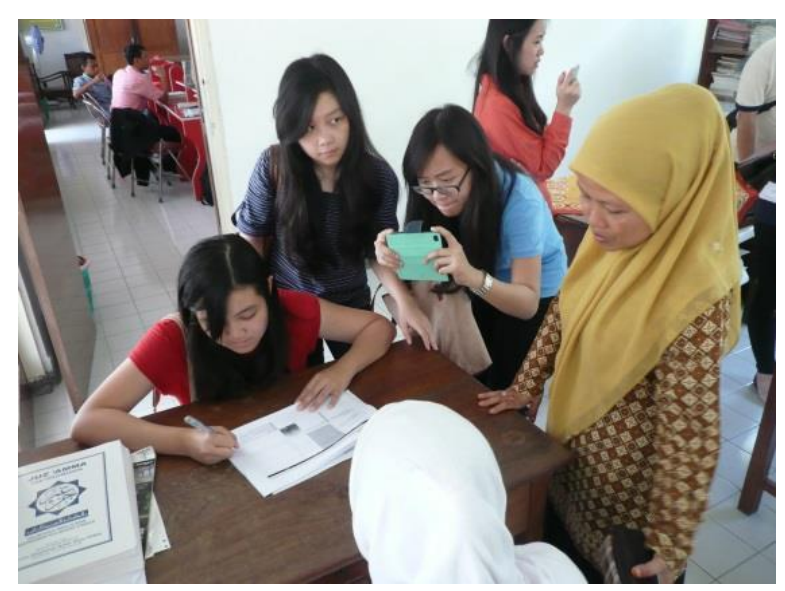

Figure 1. The Exploration of Toilets for the Blind

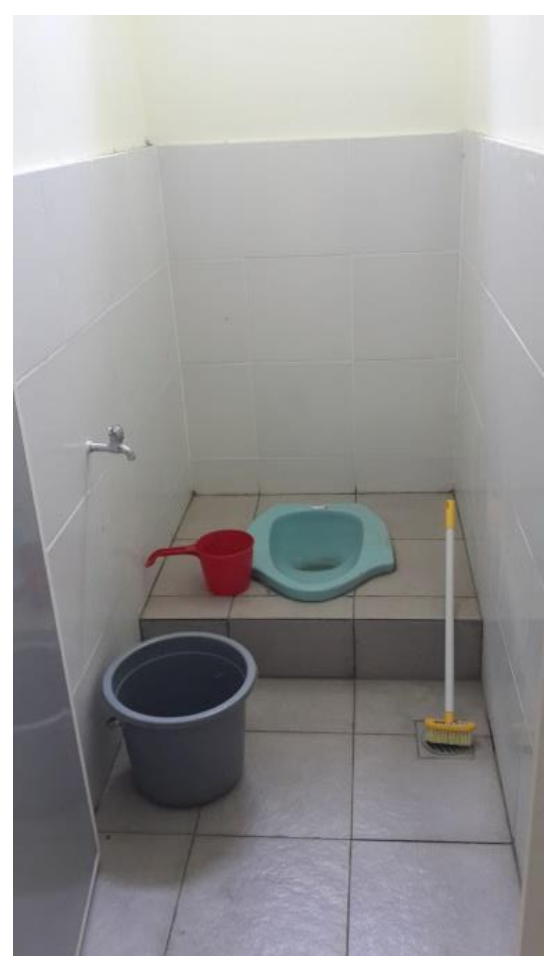

Figure 2. The Toilet in Blind School of YPAB 


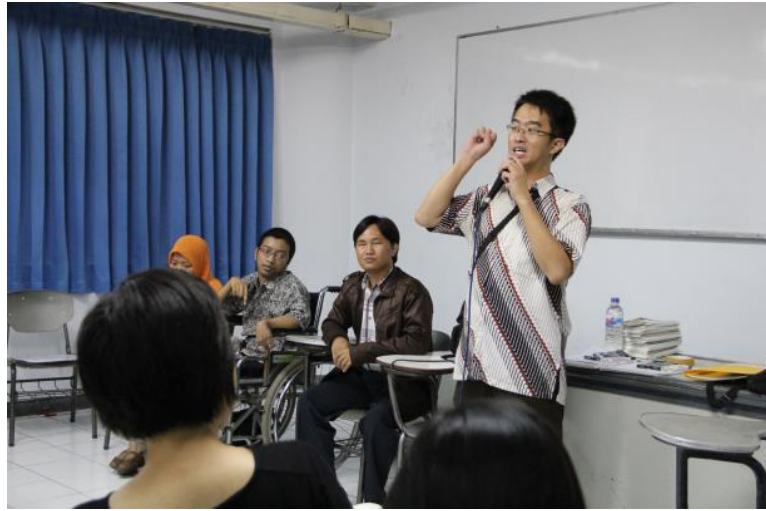

Figure 3. The Participative Toilet Design in Petra University

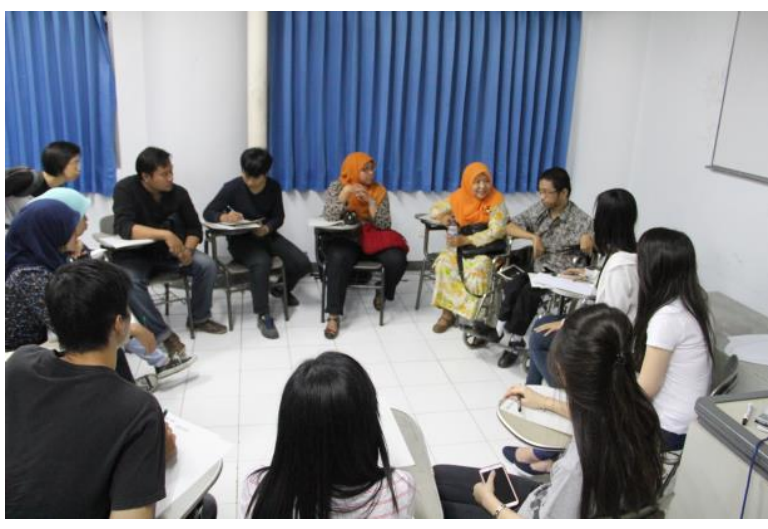

Figure 4. The Participative Toilet Design in Petra University

\section{DISCUSSION AND RESULT ANALYSIS}

The toileting culture of Surabaya people was found unique because relating to the economic, social, as well environmental context of the city.

Poverty caused unhealthy toileting culture in Surabaya, such as direct defecation into the river. Through time, the unhealthy cultures were changed because of Village (Kampong) Improvement Programs (KIP), increase of community awareness, and economic improvement.

Squatting - and - wet - toileting culture was found present in low-income urban villages / kampong and informal sectors of Surabaya. The lower income people used to the squatting - and - wet toilets because limited economy and the belief of more sacred of the water cleaning method.

On the other hand, the sitting - dry - toileting culture was found in the higher income residents. The sitting - dry - toilets were used because of the affordability of them and perception that sitting toilets were more modern.

Unfortunately, many public toilets catered only the sitting toilets. Because of poor sitting toilets, misuse of toilets happened, such as squatting on the sitting toilets.

Luckily, some commercials such as Grand City Mall provided equal number of the squatting - and wet toilets. Moreover, its toilets cleanliness was kept well.

Therefore, an inclusive design strategy was needed to provide locally friendly toilets, healthy and accessible. Based on the local behaviour exploration and participatory design, YPAB Blind School's toilet design was produced.

The inclusive design principles by Tanuwidjaja were proposed combining the Seven Principles of Universal Design and Three Principles of Inclusive Design. The Principles were:

- user centered

- equitable use but reasonable

- simple and intuitive use

- low physical effort

- prohibition of usage error

Furthermore, the explanation of each aspect was:

- USER CENTERED principle defined that the design process should involve the user, and create more useable design.

- EQUITABLE USE BUT REASONABLE aspect would include provision adequate space usage for users accessibility, but still economically viable.

- SIMPLE AND INTUITIVE USE actually represents the simple and intuitive use of the design, which supported by signage or other media such as sound, tactile, etc.

- LOW PHYSICAL EFFORT actually represents the easiness of usage by the disabled people.

- PROHIBITION OF USAGE ERROR represents that the design should not create hazard to the users. So these 5 aspects were suggested as Inclusive Design aspect in Indonesia.

The limited vision of the blind persons causes problems in interpreting things or environments. The visually impaired person relies on other senses to obtain information. So in the design, special attentions were needed.

Generally, there are two types of blindness which are: total-blindness and low-vision-blindness. Therefore, all needs of both types should be responded. The total-blind-person requires the tactile or railings for orientation and mobility, meanwhile the low-vision-blind-person needs contrasting colours for orientation. Meanwhile, he does not like the black colour for floor material because similar to the hole on the ground. 
Toileting activity the blind persons were a unique problem. The blind persons in Surabaya could use sitting toilet or a squatting toilet. They preferred the sitting toilet at home, and squatting toilet in public toilets.

The accessible water container and scoop for bathing or cleaning. The sprinklers were less favourable because could create shock during usage. They also preferred an enclosed toilet design for security and comfort. Dry area was also required in the toilets for clothes' changing.

Relating to the Design Aspects of YPAB Blind School's Toilet Design, the five aspects were achieved and described below:

- USER CENTERED principle was achieved because the toilet design was produced with the user involvement.

- EQUITABLE USE BUT REASONABLE principle was achieved because facilitating squatting and sitting behaviour. Furthermore, the toilet design would facilitate wider disabled spectrum with sliding doors and adequate spatial (outside or inside the toilet). Accommodation of bathing methods (with tub and scoop or with shower) as well as cleaning methods (wet cleaning or toilet paper) was proposed to fulfil the principle.

- SIMPLE AND INTUITIVE USE principle was achieved because it could be easily understood. The red lines with rough texture were provided in the edges. And a top flushing toilet was provided for convenient. The tub and scoop was easily located for the right handed user. The railing, wall and floor texture was also provided to guide the total-blind-person.

- LOW PHYSICAL EFFORT principle was achieved because of ramp was provided in the toilets, considering the blind person and wheelchair user. All toilet features were designed within the reach of the main users (the blind students).

- PROHIBITION OF USAGE ERROR was achieved with the non-slippery floor and wall materials, safety railing as well as rounded wall and tubs edges.

\section{CONCLUSION}

It could be concluded that toileting culture of Surabaya people was very unique because related to the economic, social, as well environmental context of the city.

Squatting - and - wet - toileting culture and the sitting - dry - toileting culture were found. Therefore, an inclusive design strategy was needed to provide locally friendly toilets but also healthy and accessible. The YPAB Blind School's Toilet Design catered five inclusive design principles. And it accommodated the blind students.

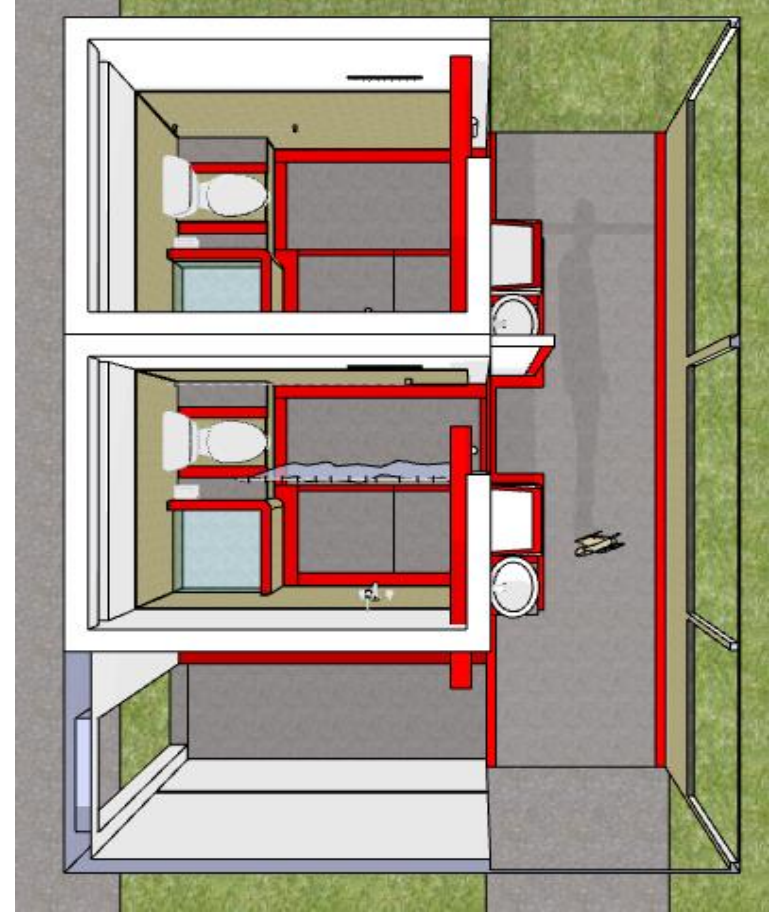

Figure 5. The YPAB Blind School's Toilet Design

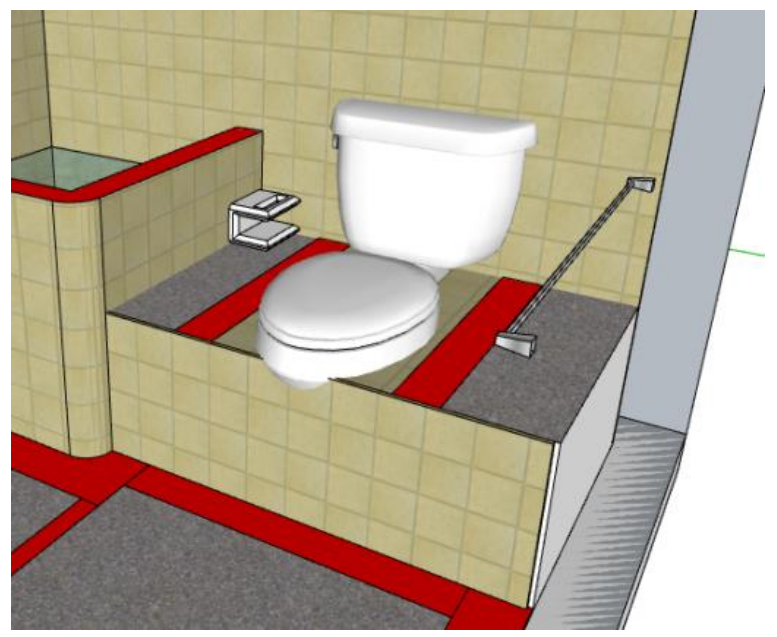

Figure 6. The Flexible toilet bowl for squatting and sitting for YPAB Blind School's Toilet Design

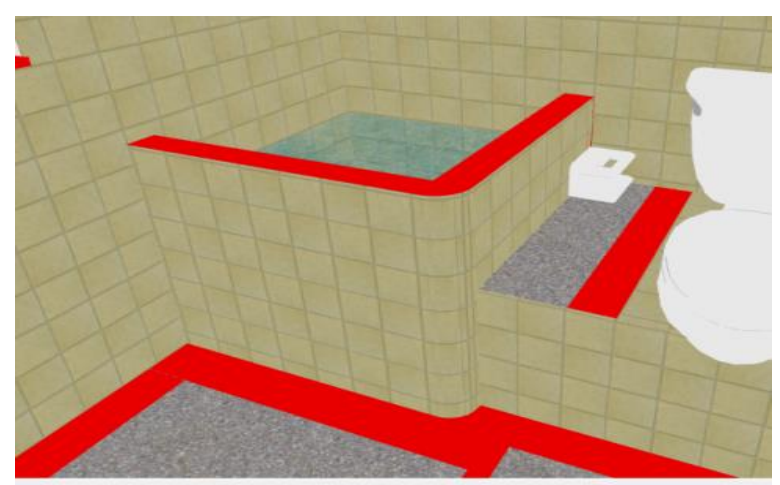

Figure 7. The curved-edges of water container and red lines to assist low vision blind colleagues to orient in Toilet Design for YPAB Blind School's Toilet Design 


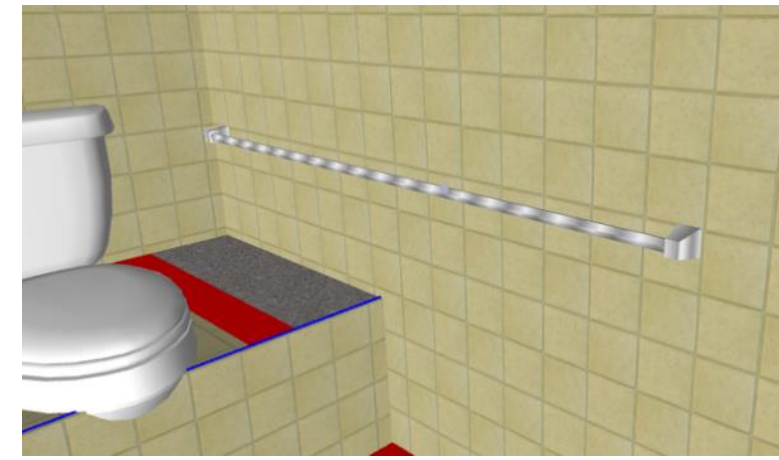

Figure 8. The railing in the YPAB Blind School's Toilet Design

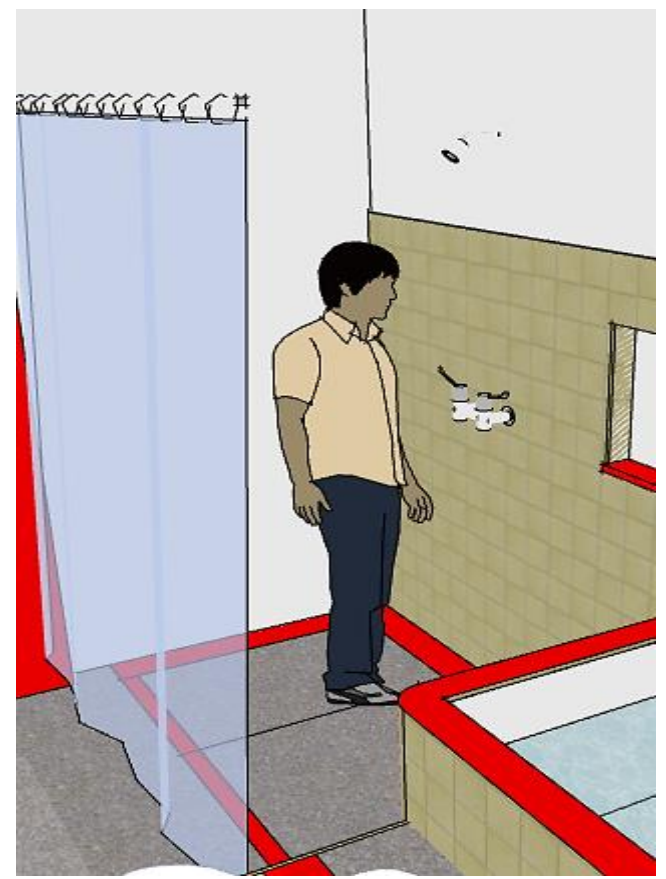

Figure 8. The bathing area with non-slippery floor material in Toilet Design for YPAB Blind School's Toilet Design

\section{ACKNOWLEDGMENTS}

We would like to thank:

- Avron Boretz Ph.D. (Former Representative of United Boards, Hongkong).

- Prof. Ir. Rolly Intan, M.A.Sc., Dr.Eng (Rector of PCU).

- Prof. Budi Widianarko (Rector of Soegijapranata Catholic University 2009-2013).

- Ir. Hanny Hosiana Tumbelaka, M.Sc., Ph.D (1 ${ }^{\text {st }}$ Vice Rector of PCU 2009-2013).

- Prof. Ir. Djwantoro Hardjito, M.Eng., Ph.D. (1 ${ }^{\text {st }}$ Vice Rector of PCU 2013 - 2017).
- Dr. Bernadeta Soedarini (Soegijapranata Catholic University, Director of UNDK Indonesia).

- Liauw Toong Tjiek, S.T., M.S. [Aditya Nugraha] (The Head of Petra Library and Board of UNDK May 2013 - March 2014).

- Agus Dwi Hariyanto, S.T., M.Sc. (The Head of Architecture Program 2009-2013).

- The UNDK Petra team: Meilinda, S.S. M.A., Erandaru, S.T., M.Sc, Heru Dwi W., M.Pd. , Obed Bima Wicandra SSn. MA., Aniendya Christianna S.Sn., Budi Prasetyadi, S.Sn. and Stefanny Irawan, S.S., MA.

- Service Learning Course C - Inclusive Design Students of Odd Semester in 2013-2014.

- C2O Library

- Ayorek! Platform

- YPAB Blind School (SMP-LB YPAB School)

- Tutus Setiawan, S.Pd.

- Ahmad Fauzi M.Hum.

- Surabaya Riverside Village Residents Association (Paguyuban Warga Strenkali Surabaya).

Other participating parties.

\section{REFERENCES}

Cummings, W. (2000). Squat Toilets and Cultural Commensurability, Journal of Mundane Behavior, published Interdisciplinary Social Science, University of South Florida.

Greed, C. (2003). Inclusive Urban Design: Public Toilets, Architectural Press, An imprint of Elsevier , Linacre House, Jordan Hill, Oxford OX2 8DP

http://desaininklusiukpetra.wordpress.com/ http://undk.asia/ http://undkpetra.wordpress.com/ http://www-edc.eng.cam.ac.uk/betterdesign Preiser, W. \& Ostroff, E. (2001). Universal Design Handbook. New York: McGraw Hill, USA.

Tanuwidjaja, G. et al. (2013). Final Report of UNDK Mini Project: Portraying the Toileting Culture of Surabaya People: People Perception, and Toilet Design Diversity, Petra Christian University, for University Network for Digital Local Knowledge Indonesia.

The British Standards Institute (2005). British Standard 7000-6:2005. Design Management Systems - Managing Inclusive Design quoted in http://www-edc.eng.cam.ac.uk/betterdesign/ 